\title{
Clinicopathological review of 1146 enucleations (1980-90)
}

\author{
Philippe de Gottrau, Leonard M Holbach, Gottfried O H Naumann
}

\begin{abstract}
The clinicopathological data of 1146 enucleated eyes obtained from 1146 patients (485 females and 661 males; mean age 57.4 (SD 21.6) years) between 1980 and 1990 were reviewed. The most common underlying diseases included trauma $(37.4 \%)$, malignant tumours (19.6\%), systemic diseases (diabetes, vascular diseases) $(17 \cdot 1 \%)$, surgical diseases (retinal detachment, glaucoma, cataract, corneal dystrophy) (14.1\%), infection and inflammation (7\%). The most frequent indications for enucleation were secondary angle closure glaucoma $(34.9 \%)$, ocular malignant tumours $(21.7 \%)$, atrophia or phthisis bulbi $(\mathbf{1 8 . 7 \% ) , ~ o c u l a r ~ i n f e c t i o u s ~ o r ~ i n f l a m m a t o r y ~}$ disease $(14 \cdot 7 \%)$, and recent trauma (enucleation was performed within the first month after trauma) (11.2\%). Histopathologically, diagnoses included secondary angle closure (691 eyes or $60.3 \%$ ), rubeosis iridis (550 or $48 \%$ ), endothelialisation of the iridocorneal angle (198 or $17 \cdot 3 \%$ ), and retrocorneal membrane (143 or $12.5 \%)$. These data indicate that rubeosis iridis, often followed by irreversible secondary angle closure, represents the most common pathogenetic reason for enucleating eyes. Management procedures must be directed towards the prevention or consequent therapy of rubeosis iridis.

(Br F Ophthalmol 1994; 78: 260-265)
\end{abstract}

Most enucleations are the result of end stage diseases or failed therapy. A recent study showed a decreasing incidence of enucleation during the past decade, but the mean annual age and sex adjusted incidence per 100000 population is still $2 \cdot 8 .{ }^{1}$ To evaluate the main reasons for enucleation, and to better understand the different pathological steps that may lead to an enucleation, we reviewed a large series of eyes. This study may help the clinicians to realise the importance of some irreversible dramatic ocular changes and to reduce the number of enucleations by appropriate prior therapy.

Department of

Ophthalmology and Eye Hospital, University of Erlangen-Nürnberg, Schwabachanlage 6, D-91054 Erlangen, Germany

P de Gottrau

L $M$ Holbach

G O H Naumann

Correspondence to: P de Gottrau, Clinique d'Ophtalmologie, Hôpital Cantonal Universitaire, 22 rue Cantonal Universitaire, 22 Genève 14 , Switzerland.

Accepted for publication 23 September 1993
(538 or $46.9 \%$ ) and from various eye clinics or hospitals $(608$ or $53.1 \%)$. Of these, 598 were from Germany and 10 from other western European countries. These eyes can be considered as representative because our laboratory has no particular subspecialisation. All clinical data were collected from the questionnaire accompanying the eye at its arrival in the laboratory. Firstly, we divided the eyes in seven groups (by primary cause of enucleation): trauma, malignant tumour, systemic diseases (which include diabetes mellitus, local or diffuse vascular diseases), surgical diseases (which include surgically treated and untreated ocular diseases like retinal detachment, primary glaucoma, cataract, or corneal dystrophy), infectious or inflammatory diseases (which include only localised and not systemic diseases), miscellaneous diseases, and, finally, those that were impossible to classify because of absent or incomplete data. Secondly, we analysed the eyes according to the indication for enucleation (last clinical diagnosis before enucleation or immediate cause of enucleation): secondary angle closure glaucoma, intraocular malignancy (or suspicion of), atrophia or phthisis bulbi, ocular infectious or inflammatory disease, recent trauma (where enucleation was performed within the first month after trauma), and not enough available clinical data. Thirdly, for the histopathological evaluation, $96.9 \%$ (1111) of the sections (each with haematoxylin and eosin and periodic acid Schiff (PAS) stains) were reviewed by PG and the rest by GOHN. The criteria for rubeosis iridis or neovascularisation of the iris were defined by the presence of new vessels, which were particularly located at the iris sphincter and at the iridocorneal angle. ${ }^{2}$ For some eyes, it was not possible to determine the presence of rubeosis iridis because of aniridia, long standing diffuse anterior synechiae, necrosis of iris tissue, or 'burnt-out' rubeosis iridis. Criteria for endothelialisation of the iridocorneal angle were defined by the presence of endothelial cells, with or without formation of a new PAS positive basal membrane, in the iridocorneal angle. The data were analysed by statistical methods (mean value, standard deviation, range, binomial test).

\section{Results}

Eyes were obtained from 661 males $(57 \cdot 7 \%)$ and 485 females $(42 \cdot 3 \%)$. There were statistically more males in the trauma group (338/90, $\mathrm{p}<0.0001$, binomial test), more females in the systemic diseases group $(81 / 115, p=0.018)$ and in the infectious or inflammatory diseases group $(30 / 50, p=0.034)$, but no sex predominance in the malignant tumour group $(111 / 114, p=0.89)$ or in the surgical diseases group $(74 / 88, \mathrm{p}=0 \cdot 307)$ (Fig 1). The patients' mean age for 1134 eyes (for 12 , the age was unknown) was $57 \cdot 4(\mathrm{SD} 21 \cdot 6)$ years (male 53.1, female 63.2) with a range from 0.2 to 95 years. For traumas $(n=426)$, it was $44 \cdot 2(20 \cdot 4)$ 


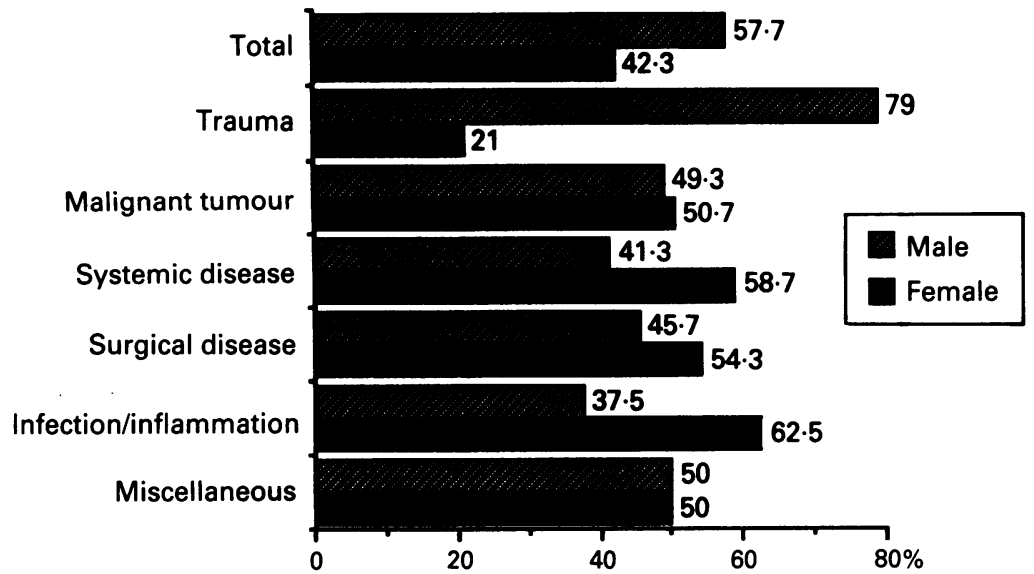

Figure 1 Sex distribution for each aetiology.

(3-95); for malignant tumours $(n=222) 60.9$ (19.2) (0.5-89) with a marked difference between the retinoblastomas $(n=13) 2.4(1 \cdot 7)$ $(0.5-7)$ and malignant melanomas of the uvea $(\mathrm{n}=208) \quad 64.8 \quad(12.6) \quad(28-89)$; for systemic diseases $(n=192) \quad 70.7 \quad(14.2) \quad(19-91)$; for surgical diseases $(n=161) 66 \cdot 1(17 \cdot 1)(0 \cdot 2-88)$; for infectious or inflammatory diseases $(n=78)$ 67.6 (17.9) (17-91); for the miscellaneous diseases $46.3(26 \cdot 1)(2-84)$; and for the not classified 63.6 (19.8) (3-90) (Fig 2). Aetiologically, there were $428(37 \cdot 4 \%)$ traumas, 225 (19.6\%) malignant tumours, $196(17 \cdot 1 \%)$ systemic diseases, $162(14 \cdot 1 \%)$ surgical diseases, $80(7 \%)$ infectious or inflammatory diseases, 16 $(1.4 \%)$ miscellaneous diseases, and $39(3.4 \%)$ that could not be classified because of incomplete clinical data (Fig 3). Subgroups are summarised in Tables 1-4. The immediate reasons for enucleation were: $400(34.9 \%)$ secondary angle closure glaucomas; $249(21 \cdot 7 \%)$ malignant tumours or suspected malignant tumours; 214 $(18 \cdot 7 \%)$ atrophia or phthisis bulbi; $168(14 \cdot 7 \%)$ infectious or inflammatory diseases; $128(11 \cdot 2 \%)$ acute traumas, and $34(3 \%)$, that could not be classified because of incomplete clinical data (Figs 4 and 5). For 44 eyes, there were more than one immediate cause. Histopathologically, we found $691(60.3 \%)$ secondary angle closure (18 were incomplete), $550(48 \%)$ rubeosis iridis, 198 $(17 \cdot 3 \%)$ endothelialisations of the iridocorneal angle, and $143(12.5 \%)$ retrocorneal membranes ( 23 were incomplete). We did not include 15 eyes with iridocorneal infiltration of the iridocorneal angle by a malignant melanoma of the uvea in the group of secondary angle closure (Fig 6).

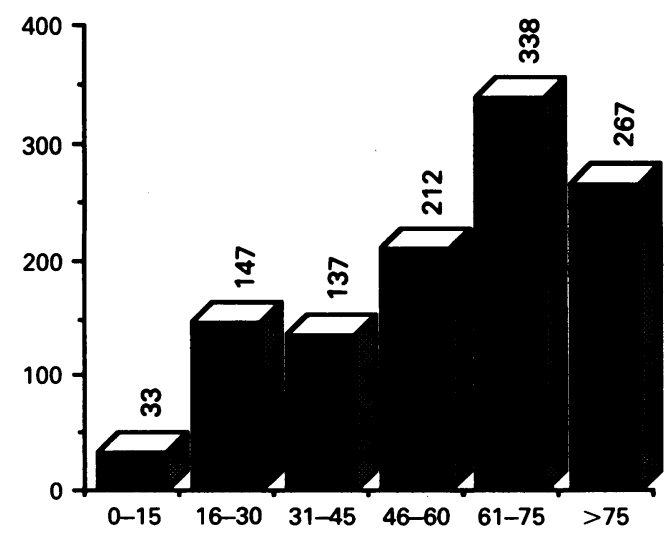

Figure 2 Age distribution.

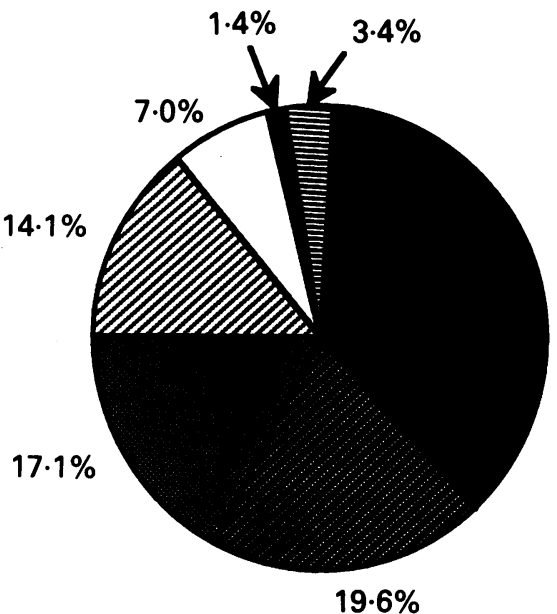

$37 \cdot 4 \%$

$19 \cdot 6 \%$

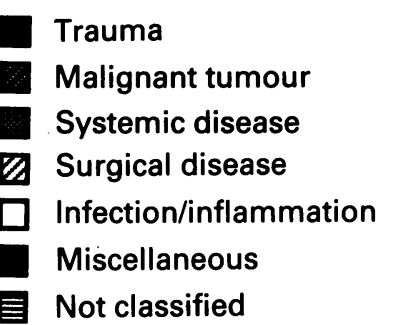

Figure 3 Aetiology distribution.

\section{Discussion}

SEX AND AGE DISTRIBUTION

As in previous studies, this present study reports a clear predominance of male patients undergoing an enucleation. Erie et al found $55.6 \%$ male and $44.4 \%$ female, ${ }^{1}$ Naumann and Portwich $59 \cdot 1 \%$ and $40.9 \%,{ }^{3} \mathrm{Lim}$ and Cinotti $59 \cdot 2 \%$ and $40 \cdot 8 \%,{ }^{4}$ Batten $58 \cdot 7 \%$ and $41 \cdot 3 \%$, and Davanger $64.3 \%$ and $35 \cdot 7 \% .^{6}$ In the aetiological subgroups, this predominance is much higher in the larger one, trauma (79\% and $21 \%)$, a percentage similar to that reported by Freitag

Table 1 Systemic diseases

Central retinal vein obstruction (CRVO)

Central retinal artery obstruction

Associated with CRVO

Proliferative hypertensive retinopathy

Proliferative hypertensive retinopa

Proliferative diabetic retino
Associated with CRVO

Pseudoexfoliation syndrome with CRVO

Sarcoidosis

Coats' disease

Wegener's disease

Behçet's disease

Lyell disease

Total .

Table 2 Surgical diseases

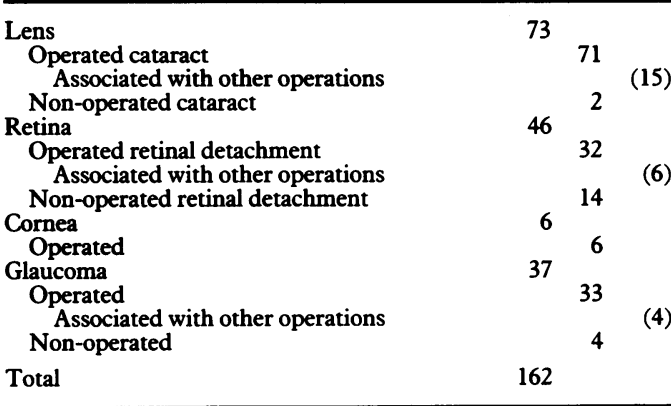


Table 3 Infectious/inflammatory diseases

\begin{tabular}{lrr}
\hline Keratitis & 52 & \\
$\quad \begin{array}{l}\text { Suspected or diagnosed herpes } \\
\text { Endophthalmitis/panophthalmitis }\end{array} \quad 16$ & 17 \\
$\begin{array}{c}\text { Candida } \\
\text { Iridocyclitis }\end{array}$ & 6 & 2 \\
Chorioretinitis & 3 & \\
$\quad$ Toxoplasmosis & 2 & 1 \\
Chronic uveitis & 1 & \\
Unclassified chronic periphlebitis & 80 & \\
Total & 2 & \\
\hline
\end{tabular}

Table 4 Miscellaneous diseases

Microphthalmia

Myopia magna

von Recklinghausen disease

2 Carcinoma of the Meibomian gland with exenteration of

the orbita

Local irradiation for non-ophthalmic tumour

Globe obtained from patient who died a few hours after

cataract operation

Total
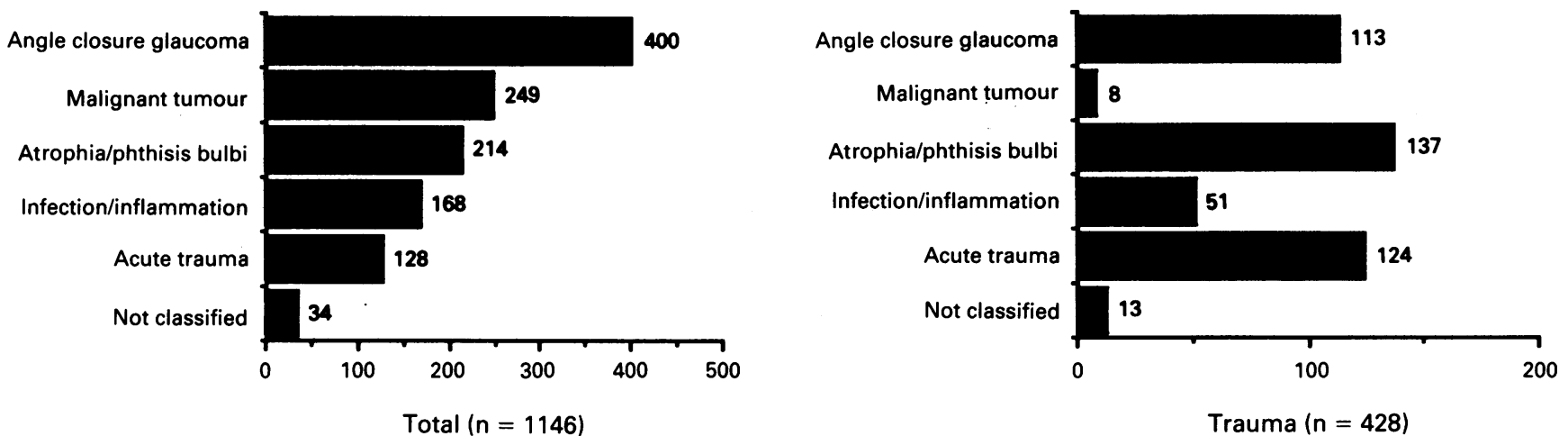

Trauma $(n=428)$
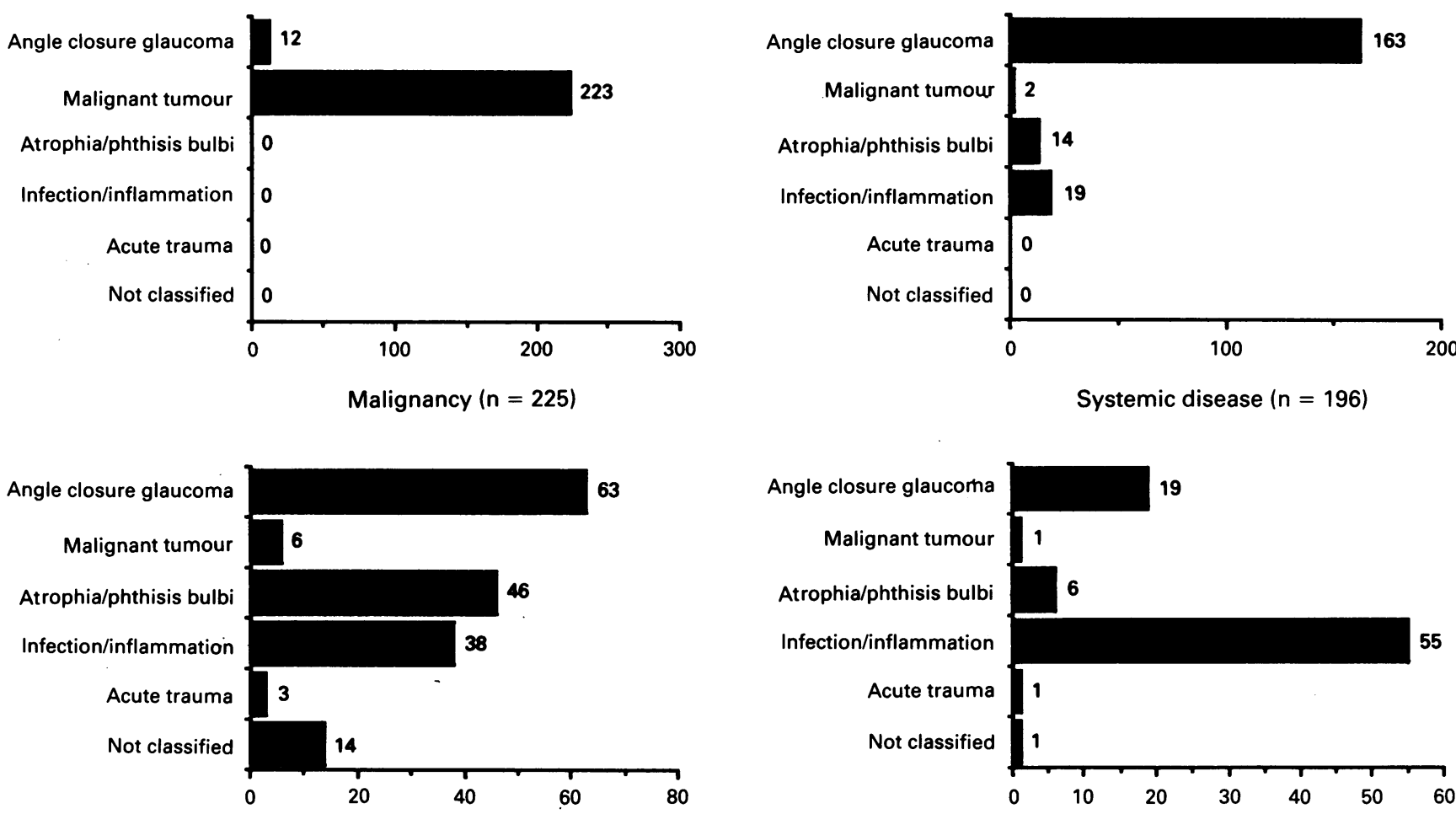

Surgical disease $(n=162)$
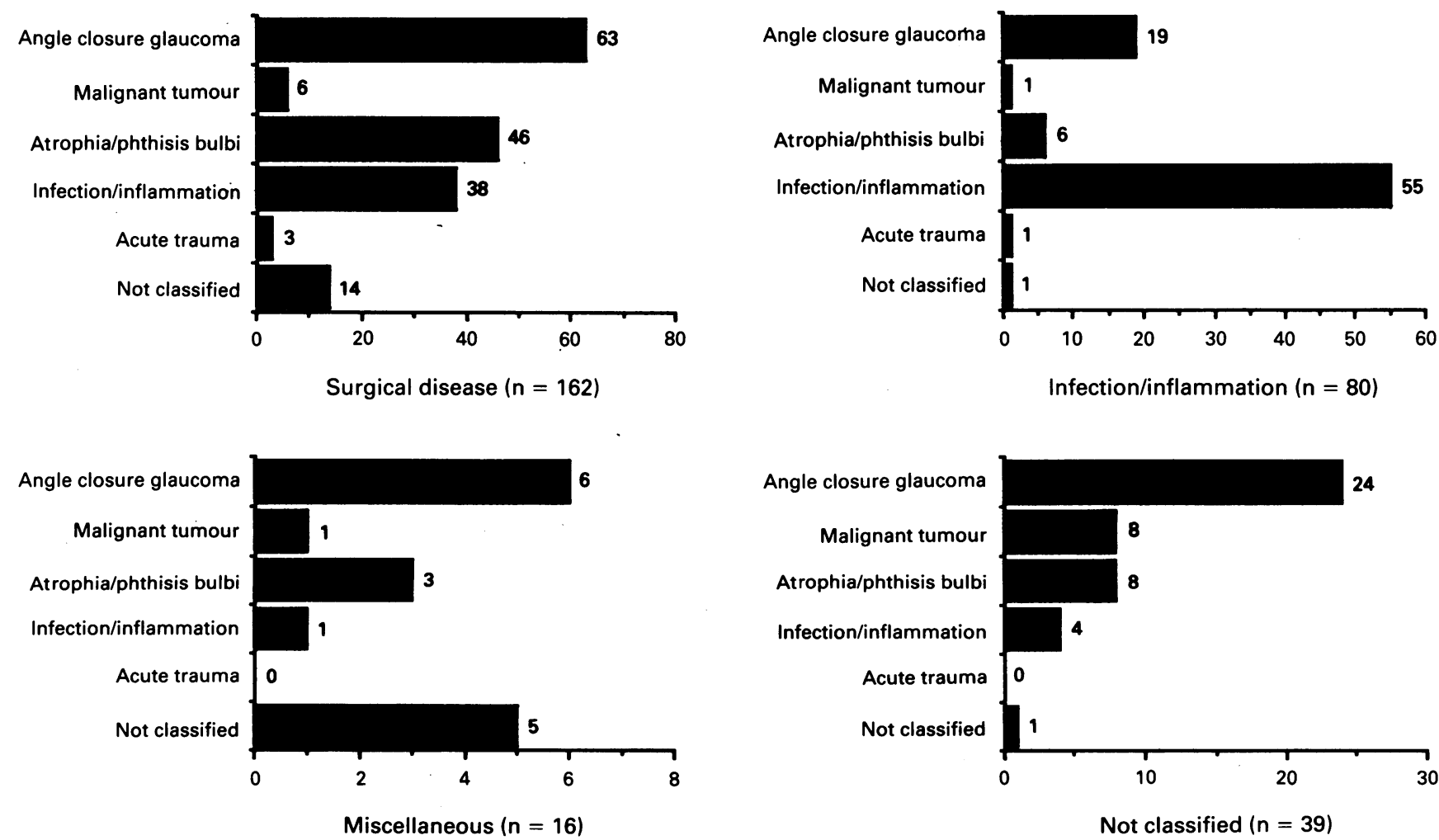

Not classified $(n=39)$

Figure 4 Indication (or immediate cause) for enucleation, for all bulbi and for each group. 
et $\mathrm{al}^{7}(75 \%$ and $25 \%)$ or Stefani ${ }^{8}(87 \cdot 8 \%$ and $12 \cdot 2 \%)$. However, there are more females in the systemic diseases or infectious/inflammatory diseases groups, and no statistical differences between male and female in malignant tumour, surgical, and miscellaneous diseases groups.

As expected, the enucleated patients after trauma are younger than the other groups, except for the group of miscellaneous diseases, where most patients have a microphthalmus. This study reports a mean age for the traumas of $44 \cdot 2$ (SD 20.4) years (range 3-95) and for all bulbi of $57 \cdot 4(21 \cdot 6)(0 \cdot 2-95)$. Freitag et $a l^{7}$ reported for trauma 39 years $(8-80)$ and Erie et $a l^{1}$ for all enucleated eyes $46(0 \cdot 8-87)$. If the peak incidence of enucleations is between age 61 and 75, it is important to remember that about $44 \%$ of all our enucleations were performed during the active life of the patient (range 16-60) and that $39 \%$ of these patients $(192 / 496)$ had some other aetiology than trauma. For comparison, Lim and Cinotti, in a study of 890 eyes enucleated between 1947 and 1969, found two peak incidences of enucleation (age 41-55 with $198 / 890$ and age 56-70 with 205/890) and it is possible to calculate that $43 \%$ of all enucleations were performed between the ages of 21 and $55 .^{4}$

AETIOLOGIES AND INDICATIONS FOR ENUCLEATION In general, the comparison with other studies is difficult, because the definitions of the groups are not always similar (except for the study of Naumann and Portwich with 1000 eyes $^{3}$ and because there are different geographic referral areas for each eye hospital receiving enucleated eyes. Nevertheless, trauma is always the largest group, ${ }^{13-68-10}$ often followed by the malignant tumour group. For the other groups, the comparison with the study of Naumann and Portwich ${ }^{3}$ reveals similar percentages for infectious and inflammatory diseases $(7.1 \%$ for their study and $7.0 \%$ for the present study), but an inversion between systemic diseases and operaindications for enucleation (with percentages) for each group. In some groups, the total percentage exceeds $100 \%$ because a few eyes had more than one indication for enucleation.

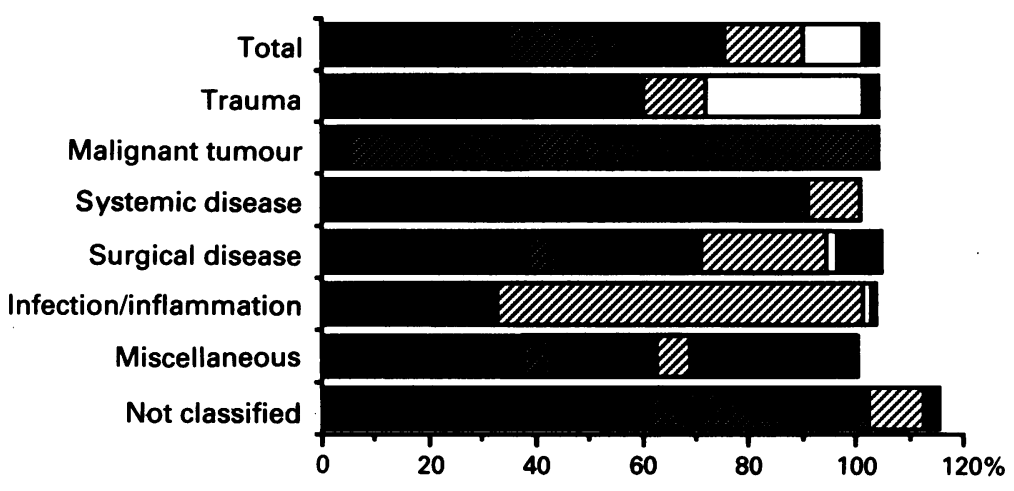

Angle closure glaucoma

Suspected malignancy

Atrophia/phthisis bulbi

$\square$ Infection/inflammation

Acute trauma

Not classified
$12 \cdot 8 \%$ to $17 \cdot 1 \%$ and the second has decreased from $16 \cdot 4 \%$ to $14 \cdot 1 \%$. The composition of these two groups has also changed. In the first one, the proportion of central retinal vein occlusions $(53.1 \%$ to $57.6 \%)$ and proliferative diabetic retinopathies $(23 \cdot 5 \%$ to $32 \cdot 7 \%)$ has increased. In the second one, the proportion of the lens subgroup has increased $(25 \%$ to $45 \cdot 1 \%)$, and the proportion of the glaucoma subgroup decreased $(40.9 \%$ to $22 \cdot 8 \%)$. Explanations are difficult to find: for the systemic diseases, there is a higher incidence of diabetes mellitus among the population and a longer life expectancy (Naumann's study took place more than 15 years ago), but, in contrast, there are now more possibilities to treat and prevent these diseases. For the surgical diseases, more cataract surgery is probably performed today, but the techniques have improved considerably both in the field of cataract and glaucoma surgery. Another interesting point is the constantly high proportion of herpesvirus infections in the group of infectious and inflammatory diseases, despite improved therapeutic methods (there are $18 \cdot 3 \%$ (13/71) of suspected or diagnosed herpetic infections in Naumann's study ${ }^{3}$ and $21 \cdot 3 \%(17 / 80)$ in the present study!).

The results of this study also confirm that secondary angle closure glaucoma, most often a neovascular glaucoma, represents the main indication for enucleation (34.9\%). ${ }^{13568}$ This percentage could be higher if all phthisis and atrophia bulbi, which are in fact burnt out or overtreated angle closure glaucoma, were included. Another interesting aspect is that $2 \cdot 3 \%$ of all the eyes (26/1146) were enucleated with a false suspicion of intraocular tumour (Naumann and Portwich ${ }^{3}$ found the same percentage!). However, only two malignant melanomas were clinically misdiagnosed.

\section{HISTOPATHOLOGICAL FINDINGS}

According to the clinical findings, the most frequent histopathological findings are secondary angle closure and rubeosis iridis $(60.3 \%$ and $48 \%$ ). Excluding all bulbi, which were enucleated in the acute phase (where secondary angle closure and rubeosis iridis had not enough time to develop), and all malignant tumours, the percentages are much higher $(79.9 \%$ and $63.9 \%)$.

Endothelialisation of the iridocorneal angle is less frequent, but was detectable nevertheless in $17 \cdot 3 \%$; it was the most often misdiagnosed pathological finding found when we reviewed the histological sections. For comparison, there are only a few studies with large series of bulbi. Pabst-Hofacker and von Domarus" reported that $53.3 \%$ of all enucleated eyes $(960 / 1800)$ had a secondary angle closure and only $8.02 \%$ an endothelialisation of the iridocorneal angle (77/ 960); Ruprecht and Naumann ${ }^{12}$ found $28 \cdot 7 \%$ $(175 / 610)$ and $16 \%(28 / 175)$. If we accept the concept that most secondary angle closures follow rubeosis iridis ${ }^{213}$ and that a total angle closure is not compatible with a long term survival of a visual acuity, we must be convinced that secondary angle closure must be avoided by treating or preventing rubeosis iridis. Practically, for the clinicians, that means that additional 

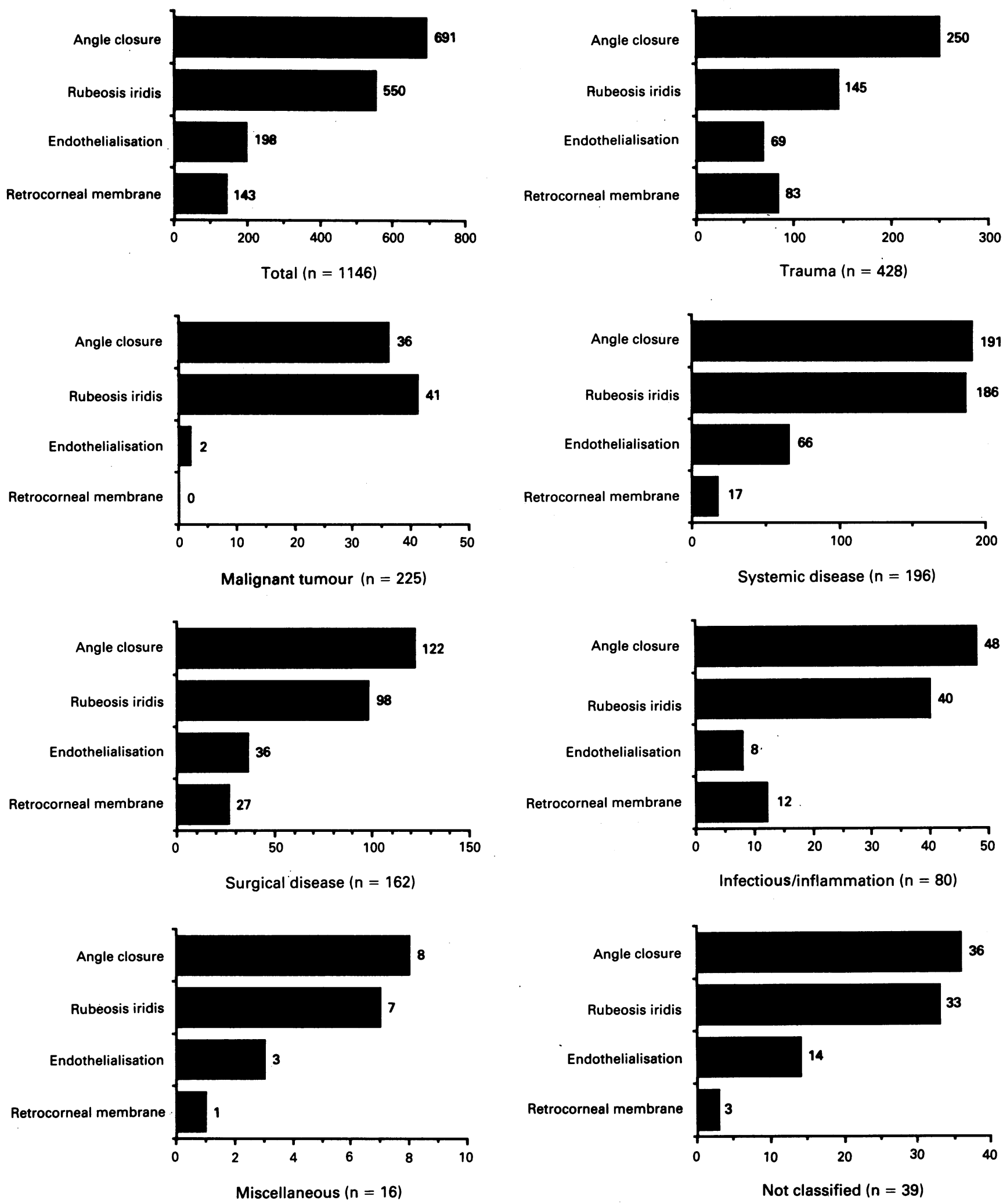

Figure 6 Histopathological findings, for all bulbi and for each group.

effort must be directed at the group of systemic diseases using panretinal photocoagulation and, in the group of surgical diseases, by increasing the success rate of the surgical procedures.

\section{Conclusion}

The clinicopathological review of 1146 enucleations indicates that trauma is always the most important factor for enucleation, that nearly every second enucleated patient is below the age of 60 , and that rubeosis iridis and secondary angle closure are the major pathogenetic reasons for enucleation. These indications must help clinicians to continue to diminish the incidence of enucleation.

This work was presented in part at the French Society of Ophthalmology Annual Meeting, Paris, May 1993.

This work was supported by a grant from the Florian Verrey Foundation, Lausanne, Switzerland.

The authors thank Mrs C Rummelt, A Händel, and D Dickson for their assistance.

1 Erie JC, Nevitt MP, Hodge D, Ballard DJ. Incidence of enucleation in a defined population. Am f Ophthalmol 1992; 113: $138-44$. 
2 Gartner S, Henkind P. Neovascularization of the iris (rubeosis iridis). Surv Ophthalmol 1978; 22: 291-312.

3 Naumann GOH, Portwich E. Aetiologie und letzer Anlass zu 1000 Enukleationen (eine klinisch-ophthalmologische Studie). Klin Monatsbl Augenheilkd 1976; 168: 622-30.

$4 \mathrm{Lim} \mathrm{JKS}$, Cinotti AA. Causes for removal of the eye: a study of 890 eyes. Ann Ophthalmol 1976; 8: 865-9.

5 Batten KL. Causes of enucleation as seen in Jerusalem. $\mathrm{Br} \mathcal{F}$ Ophthalmol 1971; 55: 174-6.

6 Davanger $M$. Causes of enucleation in Uganda. $\mathrm{Br} \mathrm{f}$ Ophthalmol 1970; 54: 252-5.

7 Freitag SK, Eagle RC Jr, Jaeger EA, Dunn ES, Jeffers JB. An epidemiologic and pathologic study of globes enucleated epidemiologic and pathologic study of globes enucl

8 Stefani FH. Phthisis bulbi - an intraocular floride proliferative reaction. Dev Ophthalmol 1985; 10: 78-160.
9 Rohrbach JM, Steuhl KP, Thiel H-J. 125 jahre Ophthalmopathologie in Tübingen. Klin Monatsbl Augenheilkd 1992; 201: 200-5.

10 Bettmann JW Jr. Pathology of complications of intraocular surgery. Am f Ophthalmol 1969; 68: 1037-50.

11 Pabst-Hofacker M, von Domarus D. Die Endothelialisierung der Vorderkammer (Klinik und Histopathologie). Klin Monatsbl Augenheilkd 1980; 177: 174-9.

12 Ruprecht KW, Naumann GOH. Zur Klinik und Histopathologie der Rubeosis Iridis. Ber Dtsch Ophthalmol Ges 1979 76: 797-9.

13 Gartner S, Taffet S, Friedman AH. The association of rubeosis iridis with endothelialisation of the anterior chamber: report iridis with endothelialisation of the anterior chamber: report additional cases. Brf Ophthalmol 1977; 61: 267-71.

\section{History of ophthalmology}

\section{Feuds between opticians and ophthalmologists}

Ophthalmologists have always relied on accessory trades to ply their practice, never having shown any inclination to grind their own lenses. Yet when the spectacle makers' charter was granted by Charles I in 1629, the science of refraction was unknown. As it developed in the late nineteenth century, both craftsman and ophthalmologist began to step into the new field. Unsurprisingly, they soon clashed, and the optician/ophthalmologist feud was reported in the medical press in more colourful terms than we would venture today!

The editor of the Ophthalmologist reported with distaste that a Kent optician was advertising 'such elaborate apparatus in his "consulting rooms" that he was able to give the best advice in every respect of the visual organs.' It is reported that this 'optician evidently desires to set up as an ophthalmic surgeon.' The editor hopes that his 'surgical proclivities will not lead him into the clutches of the law'.

The opticians' use of private sight testing rooms, to 'ape the consulting rooms of the medics' was widely criticised in medical journals. At more than one point, the 'audacity of baser members of the optical trade' is described as astonishing.

Nevertheless, it was clear that legislation on these new 'opticians' would be necessary, and Britain, France, and the United States began deciding on terms. On 27 May 1908, New York state legally recognised 'sight testing opticians', a fact which was reported in the Ophthalmoscope with the comment - 'more's the pity!'.

This sarcasm may have been prompted by an epidemic of exuberant publicity by 'opticians', such that even The Opticians' Trade Fournal promised to check up on 'unfortunate advertising'. The ophthalmologists took to reporting more fraudulent examples themselves. For example, the (large) poster 'Does your child complain of headache? It is probably eye defect. Consult us - we are opticians!' probably raised the blood pressure of a good number of medics.

To their credit, the 'Worshipful Company of Spectacle Makers' undertook to curb this, although they threatened that having done so, they would deal harshly with 'people who maliciously slander the optical profession'. No names were mentioned, but the phrase 'malignant medical groups' was.

By 1911, 24 states in the United States permitted 'optometry'. This situation did not please ophthalmologists, who commented in the journals that 'optometrists would fail to diagnose grave disease', that 'they were not subject to the ethical standards of a learned profession' (ouch!), and that 'their purely commercial outlook prevented them from protecting the public when their own pockets were in question'.

That year, the American Ophthalmological Committee recommended that every medical student be urgently taught to refract, presumably in anticipation of a future scourge of opticians. The French, however, took the medics' side, amending their act of 1892 such that prescribing spectacles by refraction, or indeed selling spectacles at all without a medical doctor's prescription was illegal.

In Britain there was confusion about the opticians' role for a long time, and court cases resulted. A good example from 1911 was that against Richard Thomas, a Manchester optician, who treated a lady with various spectacles over a period of 2 years. On finally consulting an ophthalmologist, the diagnosis of 'conical cornea' was made, and the lady was advised that earlier diagnosis would have helped. The prosecution held that unless an optician could detect disease of the eye, he should not be allowed to prescribe spectacles. The defence asserted that opticians did not profess to diagnose and cure disease, but merely to sell spectacles, and that this fact was widely known to the general public - caveat emptor!

As Thomas was advertising as an 'eye specialist' with designated 'consulting hours' this is debatable! The defence further countered that as doctors unanimously regarded opticians as undesirable aliens, all the medical evidence would be biased. Obviously the judge disagreed, fining the unhappy 'eye specialist' $£ 25$, presumably to the great delight of the medics.

FIONA ROMAN

Medical Press and Circular 1911; April 5: 14

Medical Press and Circular 1911; Ap

The Ophthalmoscope 1908; VI: 154.

The Ophthalmoscope 1911; XI: 161 .

Times Law Reports 1911; March 16 and 17. 